\title{
Family Communication in Inherited Cardiovascular Conditions in Ireland
}

Author: Sinead Whyte, Trainee Genetic Counsellor

Institute of Medical Genetics, All Wales Medical Genetics Service, University Hospital of Wales, Cardiff, CF14 4XW

Tel: 02920742610

Fax: 02929748966

Email: Sinead.whyte1@nhs.net

Sinead Whyte ${ }^{1}$ Andrew Green ${ }^{2} \&$ Marion McAllister ${ }^{1}$ \& Hannah Shipman ${ }^{3}$

1 Centre for Medical Education, School of Medicine, Institute of Medical Genetics, Cardiff University, Heath Park, Cardiff, CF14 4XW

2 National Centre for Medical Genetics, Our Lady's Hospital, Crumlin, Dublin 12, Ireland

3 Department of Clinical Genetics, PO Box 134, Addenbrooke's Hospital NHS Trust, Cambridge CB2 OQQ

\begin{abstract}
Over 100,000 individuals living in Ireland carry a mutated gene for an inherited cardiac condition (ICC), most of which demonstrate an autosomal dominant pattern of inheritance. First-degree relatives of individuals with these mutations are at a 50\% risk of being a carrier: disclosing genetic information to family members can be complex. This study explored how families living in Ireland communicate genetic information about ICCs and looked at the challenges of communicating information, factors that may affect communication and what influence this had on family relationships.
\end{abstract}

Face to face interviews were conducted with nine participants using an approved topic guide and results analysed using thematic analysis. The participants disclosed that responsibility 
to future generations, gender, proximity and lack of contact all played a role in family communication. The media was cited as a source of information about genetic information and knowledge of genetic information tended to have a positive effect on families. Results from this study indicate that individuals are willing to inform family members, particularly when there are children and grandchildren at risk, and different strategies are utilised. Furthermore, understanding of genetics is partially regulated not only by their families, but by the way society handles information. Therefore, genetic health professionals should take into account the familial influence on individuals and their decision to attend genetic services, and also that of the media.

\author{
Key Words \\ Inherited Cardiac Conditions \\ Family
}

Communication

Genetics

\title{
Introduction
}

\section{Introduction}

Inherited cardiac conditions (ICCs) are a group of disorders that are genetically and clinically heterogeneous; in Ireland it is estimated that over 100,000 individuals carry a mutated gene for an ICC (Green et al, 2006). A diagnosis of an ICC in a family affects a wide network of individuals that are genetically related, due to the risk of sudden cardiac death (SCD) (Smets et al, 2008). When disclosed, genetic risk information about an ICC enables family members to make decisions regarding medical interventions, surveillance and genetic testing. However, communication of genetic information is a complex process and can be influenced by family dynamics and understanding (Gaff et al, 2007). The aim of this qualitative study was to gain insight into the communication process, the factors that may affect family 
communication, the challenges of communicating genetic information to relatives and the influence that communication has on family relationships.

When a genetic diagnosis has been made in a family, individuals and families are faced with decisions about what information to tell their relatives, how and when to tell them, how much to tell them about the results of their test, and what the results mean for those relatives (Ashida et al, 2009, Patenaude et al, 2006). Furthermore, it appears that there are unique communication difficulties regarding genetic risk information for an ICC due to the risk of SCD in family members and individuals' uncertainty about the benefits of testing, although these difficulties were only identified in a single, small scale study (Smart, 2010). Recently, Ormondroyd et al. (2014) suggested that lifestyle is a major contributor in the perception of causation in cardiac disease. Individuals with a family history of an ICC that caused a SCD also suggested that other factors, such as an unhealthy lifestyle of the individual, contributed to the tragic event. The risk of ICCs may be modified by lifestyle factors and these individuals described a sense of motivation to adhere to lifestyle recommendations following a genetic diagnosis of an ICC (Ormondroyd et al, 2014). Furthermore, one of the factors that caused high levels of distress reported amongst parents with children who had a genetic diagnosis of LQTS was compliance with medication and lifestyle restrictions (Farnsworth et al, 2006). Therefore, communications about genetic diagnosis in families may be impacted by the lifestyle of the individual.

Research has shown that, following disclosure of genetic information, there can be parental guilt, tendencies to overprotect carrier children and survivor guilt of non-carrier siblings (Aatre and Day, 2011). When considering communication about ICCs, some individuals were concerned about informing elderly members of a family as they argued that elderly relatives would feel 'guilt' about passing on the condition. Also, some individuals stated that elderly relatives probably would not be at risk since the conditions "most often develops in the young" (Smart, 2010: p.636). Thus, the decision not to inform the elderly can pose a 
barrier in communication by limiting access to more distant relatives (Smart, 2010). However, these interviews were conducted in 2006 and 2007.

The majority of research pertaining to the family communication process about genetic information has focused on who is responsible and who in the family is informed (Gaff et al, 2007). In addition, literature on the topic of family communication has mainly focused on families that are affected by inherited cancers (Gaff et al, 2007, McCann et al 2009). The process and impact of disclosing genetic information in a family system has received less attention (Metcalfe et al, 2008). Disclosure of genetic information is described as a process rather than an act (Forrest et al, 2003). This implies that it is a collection of actions rather than a single event. If genetics health professionals rely on family members to convey genetic information, it is therefore important to gain an understanding of the process of communication of genetic information within families (Gaff et al, 2007). Furthermore, the influence of individuals' genetic test results on the communication process has received little attention. Individuals' perceptions of their own results and the influence this may have on how they communicate genetic risk information has not been explored.

Wilson et al (2004) suggest that disclosure decisions regarding genetic risk are partially influenced by the cultural background of the individuals. Cultures vary in the level of open communication with health professionals, within their immediate families, with their relatives and their community (Rolland, 2006). Families do not live in a vacuum and the vulnerability that members feel towards their increased risk of an ICC is partially determined by the way the risks are discussed in the wider society, as well as in the family (Galvin and Young, 2010). There is no qualitative research, which has explored the process of communication in families with an ICC living in Ireland and little is known about the perceived risk of an ICC in individuals living in Ireland.

This study was conducted to gain a better understanding of the process of family communication from individuals who had received either a positive or a negative predictive 
test result for Hypertrophic Cardiomyopathy (HCM) and/or Long QT syndrome (LQTS). Although these are distinctly different ICCs, there are enough similarities in their presentation to jointly examine them in a study (Smart, 2010). The information obtained from other studies on family communication has been useful for healthcare professionals as they provide an insight into patients' experiences. Genetic health professionals can further benefit from a better understanding of the process of communication of ICCs to relatives.

\section{Methods}

\section{Study Design}

This qualitative research study aimed to investigate individuals' experiences of communicating an ICC within their family. Qualitative methodologies, using semistructured interviews, are optimal as the research intended to examine participants' views and experiences. In addition, it helps to provide rich descriptions of phenomena (Pope and Mays, 1995).

\section{Sampling}

Participants for the research study were selected purposively (Richie et al, 2003) based on the inclusion criteria that all participants had undergone genetic testing for a known ICC through cascade screening at the National Centre for Medical Genetics, Ireland following genetic counselling by a cardiac genetic counsellor. None of the participations were the index case in the family. Individuals who tested either positive or negative for an ICC (HCM or LQTS) were included in the study.

Following ethical approval, the participants were recruited by a specialist cardiac genetic counsellor. All participants were selected based on whether they had previously expressed an interest in participating in research. Fifteen information packs (including an invitation letter and Participant Information Sheet) were sent from the National Centre for Medical 
Genetics. The researcher was blinded to the genetic test results of each of the participants until initial contact was made.

\section{Procedure}

The data was collected between December 2012 and June 2013. Written informed consent was provided. All interviews were conducted face to face with only the participant and the researcher present. The interview length ranged from 18 minutes to 66 minutes.

The semi-structured interviews were conducted using an approved topic guide. This focused on several topics: (a) personal experience of the condition, (b) understanding of their risk, (c) sharing information about the condition and their genetic test result in families and (d) the process of the genetic test. The interview guide allowed flexibility within the interview and minimised the researcher's influence on the participants' responses (Ulph et al, 2010).

\section{Data Analysis}

Interviews were audio recorded digitally. All audio files were transcribed verbatim and analysed using thematic analysis (Braun and Clarke, 2006). A method of constant comparison was used when undertaking thematic analysis of the transcripts (Glaser and Strauss, 1967; Strauss and Corbin, 1990). The researcher familiarised herself with the data by reading and re-reading the transcripts to generate the initial codes. The coding frames were altered and modified in light of experience and as ideas developed. They were developed to enable the identification of recurrent themes in the participants' narratives (Braun and Clarke, 2006). All interviews were coded and analysed by the researcher. The constant comparative method (Glaser and Strauss, 1967; Strauss and Corbin, 1990), which is an approach involving comparison of each individual quotation attached to a code being compared with every new instance of that code, with simultaneous development of the operational definition of that code. Emerging themes from the data are therefore grounded in the qualitative interview data. 


\section{Results}

Of the 15 participants invited to participate, nine agreed to participate, giving a response rate of $60 \%$. Participants were given the participant ID NEG or POS to indicate their DNA test result by the recruiting genetic counsellor. Four of the nine participants had a positive genetic test result and five had a negative gene test result. Two of the nine participants had a clinical diagnosis of $\mathrm{HCM}$ and all other participants were asymptomatic. All participants lived in the Republic of Ireland, but only eight of the participants were Irish National citizens, one participant was from the UK

The findings have been categorised into the macro themes and sub themes, which were identified, and each will be explored in turn below. They included; (1) dissemination of information, (2) challenges to communication and (3) impact of knowledge of condition on family. Participants had varying amounts of involvement in informing at-risk relatives of the genetic condition within their families. All participants discussed the condition with their relatives and disclosed their genetic test results to their immediate families regardless of genetic test results. Therefore, no significant difference was observed between those with a negative and a positive gene test result and their decision to inform relatives about the risk of an ICC. Eight out of the nine participants informed at-risk relatives about the inherited condition; but one participant felt that there was no one left in the family to inform. The use of [...] during a quotation indicates that other topics discussed have been removed to aid clarification. 


\section{1) Dissemination of Information}

The first theme pertains to the participants describing how the genetic information was communicated in their families. Generally, the participants preferred to be informed and to discuss genetic information directly rather than use any information tools such as letters. All participants had similar views as it allowed them to engage in a conversation or discussion with their relatives. Furthermore, the participants took a pragmatic approach to informing relatives about the condition and their immediate family about their test results.

NEG1: I prefer to sit and have a chat with somebody "Oh yeah I have done that" "Oh really and how did you get that passed on? [...] rather than sitting and looking at some typescript off the screen that doctor such a body wrote.

\subsection{Responsibility and Duty}

When they were informed about the genetic condition in their family, seven of the participants disclosed that they were concerned about the prospect of passing on the mutation to their children. This responsibility was an influential factor in prompting genetic testing. Additionally, all participants felt that the condition was very treatable and this played a factor in their decision to undergo testing.

NEG3: Both information for me so I could be clear [...] how would I manage it and then how would it impact on whether I would have the children tested.

Furthermore, the duty towards family members was reflected in discussions about disclosing information about the condition. Informing relatives of the condition and the availability of testing was often followed by remarks about the necessity to think of children and grandchildren in their decision to avail of cardiac and genetic services. This persuasive technique was cited in three participants' accounts of informing relatives. NEG4: My uncle 
in question because he was the hardest to get around [...] He has grandchildren [...] So I played devil's advocate and turned to him and said 'What if in 15 years' time he (grandchild) is playing hurling and he drops dead and it could be linked to Long QT and you didn't get tested and get your family tested to see if you are a carrier".

\subsection{Family Structure and Gender}

Five of the participants described who talked to whom within the families about both the condition itself and the test results. Unsurprisingly, a generational transmission of information was mentioned by the two participants whose parents were still alive. One participant felt that due to the fact that the condition was discovered in his brother, his mother had an obligation to inform relatives in the wider family.

POS2: Far as I was looking at it there is kind of a hierarchy view with my mother, kind of I am reporting it to my mother and she's on the same kind of level as my aunt [...] because it was her son who was initially found to have it [...] it's kind of like everything is funnelling through her.

Similarly, decisions about informing children (including adult children) about genetic risk and information, was at the discretion of the parents.

NEG4: She (aunt) still thinks of them as her little girls, which is quite tough, when you don't want to cross the boundaries of parent-child relationship and that can be hard because you don't want to lie. They are adults. 
Interestingly, when the participants were asked about discussing the condition within their families, the male participants mentioned that they would discuss the impact of the condition with all relatives. However, they felt that they would share their results with their other male relatives in a casual manner and would only discuss it briefly or not at all.

POS2: My cousin's husband *Jim [...] myself and himself would have a few chats about that you know.

However, the female respondents disclosed that they talked to both sexes but had a more open conversation with their female relatives.

POS3: I would talk to my sisters more [...] Me and my sisters are very close yeah we would be and my brother *James he would be too not so much but yeah sisters definitely we would.

\subsection{Media}

When the participants were asked about where they had got their information from when they were being informed about the condition and passing on the information, six participants had volunteered they or a member of their immediate family had looked up the condition on the internet. Interestingly, all participants acknowledged that information on the internet is not always reputable and therefore they tended to use websites, such as the Irish Heart Foundation website. However, three of the participants felt that they had been overloaded with information, which increased their worry.

POS4: I mean sometimes a little knowledge is better than too much knowledge [...] the more I read the more anxious I was getting. 
Four participants mentioned the media and celebrities within their interviews. Some of the participants had read information from newspapers about the condition and/or services available. Additionally, the participants mentioned sporting celebrities or athletes, which had allowed them to converse more easily with family and friends about the nature of the condition in their families.

POS1: Nearly always told them something like "oh well I have what Fabrice Muamba has" you know. And they're like "Oh yeah that guy" [...] Once I put it into a picture like that for them because I think if I just told people straight out "oh by the way I have Long QT". They'd be "oh that's nice". But once it's somebody they knew they can say it's very serious.

\section{2) Challenges to communication}

All participants discussed a willingness to inform other family members about the ICC in their families. However, analysis revealed that there was a range of difficulties in communicating within the family, including the size of families and awareness of who had to be informed. Lack of contact also made communication and disclosing information pertaining to the condition difficult. In some instances these factors were dependent on one another and it was often a combination of all three that made communication difficult.

\subsection{Offspring}

Interestingly, although participants encouraged family members that had children or grandchildren to have testing, a few participants volunteered that having genetic testing was only necessary for those with children or who were planning to have children. This was cited as a reason why they felt children (including adult children) do not need to have genetic testing yet. 
POS4: They (children) don't even need to get the gene test [...] they probably need the gene testing maybe if they were thinking of having children.

\subsection{Lack of Familiarity}

Family communication was often made difficult by the size of the families in past generations (typically in the participants' parents' generation). Participants described a lack of familiarity with relatives and the influence this had on not informing them about the condition in the family. The following extract reveals the interconnection between the dispersed large family network and weak relationships with some family members.

POS4: The problem was my father had eight or nine brothers and they've got a few sisters, they all had eight or nine kids so in that we as small children we saw them as cousins, but as we get older we didn't really keep in contact with them.

Two of the participants disclosed that due to relatives emigrating, communication was impeded as they had little or no contact with them in the past.

NEG1: I wouldn't know half the relations over there like there was the brothers, the dad's family, like the girls that they moved across it England in the '40s '50s and '60s. They have married and had kids and their kids got married and had kids..

Additionally, some of the participants' reasons for not informing relatives were the anticipated disinterest in the information. Following on from the lack of contact with relatives, two of the participants expressed that they did not feel as though their relatives would be proactive if provided with information about the condition.

POS2: I am not sure if they were contacted they would go and get tested.

Another felt that her relatives would struggle to understand the information passed onto them. 
POS3: We don't be in contact, do you just tell them this? I think they are just won't be bothered one way or the other [...] if you said there was something I don't think they would be able to get their head round it either you know that way.

Participants expressed the dilemma and internal conflict they faced about informing relatives where there are weak relationships, even when their relatives reside within the same county. Two of the participants were conflicted about how they would go about informing their more distant relatives.

POS3: We are not in contact with them, I am not too sure a good few of them would be in Ireland all right yeah but it would be how to get around telling them, I mean not after speaking to them in so many years then to come and tell them this, I don't know how they would take it.

It was evident from the participants' responses that proximity to their relatives played a factor in communication and knowledge of whether their family had taken steps to investigate whether they had the condition or not.

POS2: I am not sure whether they have or haven't the gene they're kind of haven't seen them in a while you know.

For those relatives and siblings that the participants saw occasionally, they were less likely to discuss the condition and testing.

POS3: I have never actually spoken to him [Brother in Scotland] about it to be quite honest and for you know no other reason than the only time I ever see him is on holidays and I don't you don't really ((chuckles)) bring it up when you're on holidays. [.....] he [another brother living in Scotland] doesn't say we probably don't bring up the subject that much you know that sort of way. It's not really spoken about with him probably 'cos \{sic\} we don't see him that much you know that sort of way. 
However, two of the participants mentioned social networking sites to overcome the geographical barrier to connect with relatives aboard and converse with them about the genetic condition.

POS1: Well Facebook is a great tool. Yeah I was able to over the years since the two ah cousins had been over from Sheffield. We gradually sort of built up a kind of a network of cousins over there. So we were able to inform them.

\section{3) Impact of knowledge of condition on family}

All interviews started with a discussion about how the individuals learned there was an ICC in their families. In their accounts, six out of the nine participants described the loss of a sibling due to SCD, whilst the remainder reported an account of relatives that have had a cardiac episode that brought about the diagnosis of an ICC.

\subsection{Strengthening bonds}

Although most participants described their families as having a close relationship, a diagnosis of an ICC within a family seems to have brought families even closer together.

POS2: Before we found out about this, we won't have sat down and talked, not seriously but in depth, well I suppose seriously we would have talked about football and you know whatever. So that would be different. I think more communication with some of my cousins because of this. Whereas maybe I won't have had as much communication had we all hadn't shared the same gene. So I would imagine that it has changed the family dynamics you know whether that's good or bad. 
Furthermore, eight of the participants disclosed that they had shared the experience of undergoing investigations for the inherited condition with family members. This experience of undergoing cardiac investigations was typically done with a sibling or a first cousin of a similar age and where there was a strong existing relationship. There was a sense of solidarity and togetherness felt by the participants when undergoing testing at the same time.

NEG2: We just said we'd go in so a few of us went in together [....] there was two, three and myself there was four of us altogether at the same time. We've just rallied around one another on it you know.

However, two individuals who tested negative whilst their relatives got positive test results expressed feelings of shock and guilt about the outcome after going through the experience together.

NEG4: The initial shock of knowing someone close to you has it. Then it was case of "No I want it why does it have to be him".

\subsection{Gaining Knowledge}

Following a diagnosis of an ICC, all participants expressed positive feelings towards learning there was a condition within their family. They were given the opportunity that other family members had not had, to gain insight into what was going on in their bodies. The response amongst the participants was similar in that they felt that it was "better to know than not know" independent of their DNA test results.

NEG4: I now know what is going on in my own body than everybody else out there or the next Joe Bloggs you run into. 


\begin{abstract}
POS3: *Anne \{Sister's name\} passing away kind of saved us because we'd never know [...] I would have never got checked or done anything about had *Anne \{Sister's name\} not died.
\end{abstract}

However, participants reported that families' reaction to the information about the inherited condition ranged from proactive to uninterested. The participants who had received a negative gene test result expressed more than those with a positive gene test that they could not understand why their relatives were not proactive about seeking a medical opinion on the inherited condition within their families. This was particularly difficult for participants to understand when their relatives had children or grandchildren.

NEG4: It'd be the one cousin but she had seven or eight grandchildren and she also has brothers and sisters here and none of them have got tested [...] I can't understand their mentality on it now really I would have thought they would have been more intelligent about it.

Furthermore, participants described having a gene mutation in the family as not particularly different from other gene mutations and therefore it did not have a large emotional impact. There was a similar sentiment felt about disclosing their DNA results to others. One participant, who is affected with LQTS, expressed that having the mutation was similar to having any other characteristic.

POS2: I didn't necessarily see it any different from having red hair or not that there is anything wrong with red hair but erm it's a thing I have no control over an you know

\title{
Discussion
}


The aim of this study was to explore communication in families with an ICC living in Ireland generated information on the impact that knowledge of an ICC has on the individual conveying the genetic information and family relationships. In order to understand why and whether information is likely to be passed on, an account of the cultural, familial and individual factors must be examined.

\section{Dissemination of Information}

The family's culture and structure may be a particularly important factor in dissemination of information, provision of support and persuasion of family members to manage their risk including screening and genetic testing (Koehly et al, 2003). An important factor in family communication was the generational responsibility towards not only their own children, but children of their relatives. This supports previous findings in families with an autosomal dominantly inherited condition in which individuals felt familial responsibility towards nieces and nephews (Forrest et al, 2003). Interestingly, several participants felt that genetic testing was only necessary for those with children or planning a family. This study found that when relatives chose not to go for testing after being informed, it was often seen as irresponsible not to take future generations into account. In fact, when some participants were informing relatives about their genetic risk, it was often discussed that the relative should think about their children and grandchildren in their decision to manage the condition. Similarly, in other inherited conditions, merely sharing risk information often did not incite relatives to seek genetic counseling and testing, and relatives were actively persuaded or coerced to seek genetic services (Peterson et al, 2003, Foster et al, 2004, Van Den Nieuwenhoff et al, 2007). This has direct implications for relatives' right 'not to know' about their own health and/or genetic status and may result in a less informed or well-considered decision to have a test. As a result these relatives may be less well prepared for the test results in the longer term. 
The type of family communication patterns can play a role in how families and their members important role in dissemination of genetic information. The relationship between family communication patterns and disclosures about genetic information has been shown in previous studies (Gaff and Bylund, 2010; Kenen et al, 2004). This study's findings showed that these families favour a communication pattern of conformity orientation (Koerner et al., 2010), in which family hierarchy is less likely to be challenged. This was evident when participants were concerned about informing an adult cousin as they did not want to disrupt the parent-child dynamics and responsibility. Additionally, the results indicate that the sample have a high conversation orientation communication pattern that allows open communication within families (Kenen et al, 2004, Wilson et al, 2004). It is important to note that conformity and conversational orientations interact consistently (Braithwaite and Baxter, 2006).

Gaff et al (2005) suggested that women felt that discussing genetic information in their family was normal, whereas men felt no such normalcy. Women were found to be more likely to take initiative to disclose information and engage in open communication with family members (Chivers-Seymour et al., 2010; d'Agincourt-Canning, 2001; Forrest et al., 2003; Forrest Keenan et al., 2005). Furthermore, women were most likely to talk to other women about the family history and predictive genetic testing as reported elsewhere (Green et al., 1997; McAllister et al., 1998). However, the present study found that there was no difference between the men and women interviewed in terms of openness and willingness to discuss genetic information with relatives. Albeit, the participants volunteered that they were unsure about whether their male relatives had gone for genetic testing and if so what their results were. The finding of no gender differences could be an artefact of the small sample size. 
The use of the internet as a source to obtain information pertaining to ICCs and genetics supports previous research, which showed that the internet emerged as a major resource in people's quests for diagnosis, prognosis, treatments, services, and supports (Schaffer et al, 2008). However, individuals did feel overloaded by the amount of information. This then raises the question of whether the public regard the internet as the best source of information on complex genetic information.

Similarly, the influence of the news and the media is an important factor in how the public learn about aspects of healthcare and importantly genetic conditions and genetic testing. Weiner et al (2005) noted that media influence was more important than both gender and ethnicity in determining knowledge, attitude and behaviours about genetics. However, the media's influence does not often lead to accurate portrayals of genetic diseases. Some research on the media's influence on the public found that it has led to public misunderstanding (Parrot et al, 2010). Yet the results of this study found that the media had a positive effect. Knowledge and recognisability of celebrities with an ICC aided communication as it allowed lay people to associate the condition with a public figure. Furthermore, as the amount of media coverage and celebrities with genetic conditions become publicized, it will continue to influence the lay publics' views on genetics and genetic conditions.

\section{Challenges to communication}

Participants in this study, and other studies, reported an openness and willingness to communicate information pertaining to the genetic condition with their family. However, some relatives remained uninformed and typically these family members were geographically or socially distant, or assumptions were made by the participants about the relevance of the information to those individuals. Similar communication issues have been reported in other studies (Forrest et al, 2003, Claes et al, 2003, Dugan et al, 2003, McCann et al, 2009). It seems that communication with more distant relatives was less likely to occur 
as there was little or no contact, therefore acting as a major barrier to informing them, and this is similar to other research findings (Green et al, 1997). Participants were conflicted and unsure of how to contact a relative with whom they had little or no contact, to provide information pertaining to the ICC. Individuals were burdened by the prospect of informing these relatives as they were unsure as to how the relatives would receive the information.

\section{Impact of knowledge of condition on family}

There are inconsistent reports that disclosing genetic information can have a negative or positive impact on a family system. Some research found that it had burdened families (Sobel and Cowan, 2000) whilst others suggest that it can strengthen familial relationships (Liede et al, 2000). Individuals are often brought together with relatives that they had little or superficial contact with, which may lead to re-establishment of relationships among family members (Finkler et al, 2003). Some participants expressed that they had experienced a new closeness in their relationship with family members, which in some cases was amplified by the loss of a close relative.

Individuals who attended for surveillance and genetic testing together described the experience positively and expressed a sense of unity. Previous studies have shown that close relatives are an important source of informational and emotional support among adults (White and Riedmann, 1992). The participants seemed to have adjusted to their results and this may have in part been due to the emotional and practical support provided by family members that were going through the experience at the same time. However, this would need to be investigated further in order to gain a better insight into whether sharing the experience of cardiac investigations and genetic testing played a role in adjustment to the diagnosis. Unsurprisingly, following the outcome of the results some participants alluded to the fact that they had experienced some 'survivor guilt' (Metcalfe et al, 2008), albeit only for a short period of time following the disclosure of the families' test results. 
Attitudes to risk information are shaped by pre-existing perceptions and by the way the information is presented (Shaw et al, 1999). The response to learning that an ICC is in their family and going for investigations was generally positive among participants. They explained that they had been given an opportunity to gain a better understanding of their own health, something that was not afforded to others that had had a sudden cardiac event. However, there had been several years since the first individuals in their family had a sudden cardiac event and therefore the passing of time may have contributed to this positive attitude.

\section{Study Limitations}

These findings need to be considered in the light of the study limitations. As this is a small scale qualitative study to identify common themes, it cannot be assumed that findings will apply to all families living in Ireland with an ICC. There were no consistent differences amongst the different participants based on their characteristics in the data analysis, but as the sample size was small, these may have been masked. In addition, there may have been a sampling and response bias as those participants in the study may have had fewer difficulties communicating. Therefore, they may have been more inclined to discuss their experiences than those who did not respond, or were not invited to take part. Furthermore, six of the nine participants had a family history of SCD. This is a rare occurrence even within families affected by ICC and therefore, the finding that identification of an ICC as the cause of SCD in the family strengthened familial bonds may not be generalizable to ICC families who have not experienced SCD. Timing of diagnosis was not discussed with the participants and it was not known whether families with a history of SCD had a known ICC diagnosis before death or if the diagnosis was post mortem. Therefore, this factor may have impacted on how families communicated about the ICC within the family. Additionally, the response of the participants who was a UK citizen living in Ireland differed from the other participants who were Irish citizens. However, it cannot be assumed that the differences are 
due to participants' nationality. Furthermore, this study is retrospective and the participants recollected events for discussion in the interview; hence on more than one occasion participants stated that they could not remember or did not know.

\section{Practice Implications}

Although the findings herein cannot be generalised, with further consideration they can aid genetic health professionals. Humans are social beings that exist within a network of relationships that is influenced by obligations and responsibilities. Therefore, it is very important to take this network into account and be aware of its influences. Coercion and persuasion were reported as being utilised by family members to encourage some relatives to seek medical and genetic opinion about the inherited condition in this study and other studies (Peterson et al, 2003, Foster et al, 2004, van den Nieuwenhoff et al, 2007). Therefore genetic counselors should help individuals to reflect on the extent to which their decisions and actions are due to a sense of familial responsibility and increasing selfawareness, and not try to eliminate the familial influence of duty and obligation as suggested by Liede et al (2000).

In previous studies, individuals felt that it would be burdensome to inform relatives (Sobel and Cowan, 2000). However, the findings from this study reported that participants experienced a strengthening of a familial bond following the diagnosis of an ICC within their family. Due to the inherited nature of genetic conditions, individuals are purposely or unwillingly brought closer to their family and therefore, the autonomous, untethered individual is brought back into the family and even into the extended family (Finkler, 2003). Additionally, it seems that some of the results could be magnified by large family size and that seems to have been the norm for these participants. Furthermore, the finding that sharing the experience of cardiac and/or genetic testing seemed to have a positive effect on relationships and adjustment to a diagnosis may have implications for genetic counseling and supporting family communication. 


\section{Implications for Future Research}

Although the findings from this small study cannot be generalised to the wider patient population, they can make genetic health professionals aware of areas for further consideration. Individuals and families do not live in a vacuum, their views on genetics and risk is partially determined by the way in which society handles the information (Galvin and Young, 2010). The results of this study suggest that the media and celebrities are an important source of information and understanding about health and genetics. Genetic health professionals' awareness of the influence of mass media is therefore important. Nowadays, individuals have access to the internet or mass media and there is an increase in the amount of reporting about genetic information. As a result of this, it would be worthwhile to increase research efforts into the relationship between genetics and media and the impact it has on individuals understanding and attitudes towards genetic services.

\section{Conclusion}


These findings help us gain an understanding of the communication processes, what influences them and the impact it has on families with an ICC in Ireland. They may also provide health professionals with an insight into how families communicate genetic risk information and what influences their decisions about who to inform. Further research is needed to assess these findings on a larger cohort of individuals to investigate whether these findings are applicable to other conditions in Ireland.

All procedures followed were in accordance with the ethical standards of the responsible committee on human experimentation (institutional and national) and with the Helsinki Declaration of 1975, as revised in 2000 (5). Informed consent was obtained from all patients for being included in the study.

\section{References}

Aatre, R. D. \& Day, S. M. (2011). Psychological Issues in Genetic Testing for Inherited Cardiovascular Diseases. Circulation-Cardiovascular Genetics. 4, 81-90.

Ashida, S., Koehly, L., Roberts, J. S., Chen, C. A., Hiraki, S. \& Green, R. C. (2009).

Disclosing the disclosure: Factors associated with communicating the results of genetic susceptibility testing for Alzheimer's disease. Journal of Health Communication. 14 (8), 768 84.

Braun, V. \& Clarke, V. (2006). Using thematic analysis in psychology. Qualitative Research in Psychology. 3, 77-101.

Chivers-Seymour, K., Addington-Hall, J., Lucassen, A. M. \& Foster, C. L. (2010). What facilitates or impedes family communication following genetic testing for cancer risks? A 
systematic review and meta-synthesis of primary qualitative research. Journal of Genetic Counseling. 19, 330-342.

Claes, E., Evers-Kisbooms, G., Boogaerts, A., Decruyenaere, M., Denayer, L. \& Legius, E. (2003). Communication with close and distant relatives in the context of genetic testing for hereditary breast and ovarian cancer in cancer patients. American Journal of Medical Genetics, Part A. 116A, 11-19.

D'Agincourt-Canning, L. (2001). Experiences of genetic risk: Disclosure and the gendering of responsibility. Bioethics. 15, 231-247.

Dugan, R. B. Wiesner, G. L. Juengst, E. T. O'Riordan, M. Matthews, A. L. \& Robin, N. H. (2003). Duty to warn at-risk relatives for genetic disease: Genetic counselors' clinical experience. American Journal of Medical Genetics, Part C. Seminars in Medical Genetics. 119C (1), 27-34.

Farnsworth, M.M., Fosyth, D., Haglund, C. and Ackerman, M.J., 2006. When I go in to wake them... I wonder: parental perceptions about congenital long QT syndrome. Journal of the American Academy of Nurse Practitioners, 18(6), pp.284-290.

Finkler, K. Skrzynia, C. \& Evans, J. P. (2003). The new genetics and its consequences for family, kinship, medicine and medical genetics. Social Science \& Medicine. 57(3), 403-412.

Forrest, K., Simpson, S. A., Wilson, B. J., Van Teijlingen, E. R., Mckee, L., Haites, N. \& Matthews, E. (2003). To tell or not to tell: barriers and facilitators in family communication about genetic risk. Clinical Genetics. 64, 317-326.

Forrest Keenan, K., Simpson, S.A., Wilson, B.J., Van Teijlingen, E.R., Mckee, L., Haites, N., \& Matthews, E. (2005). 'It's their blood not mine': Who's responsible for (not) telling relatives about genetic risk? Health, Risk \& Society. 7, 290-226. 
Gaff, C.L., Collins, V., Symes, T., \& Halliday, J. (2005). Facilitating family communication about predictive genetic testing: Probands' perceptions. Journal of Genetic Counseling. 14, 133-140.

Gaff, C. L., Clarke, A. J., Atkinson, P., Sivell, S., Elwyn, G., Iredale, R., Thornton, H., et al (2007). Process and outcome in communication of genetic information within families: a systematic review. European Journal of Human Genetics. 15, 999-1011.

Gaff, C. L. \& Bylund, C. L. (2010). Family Communication About Genetics; Theory and Practice. New York, Oxford University Press Inc.

Galvin, K. M. \& Young, M. (2010). Family systems theory. In: Gaff, C. L. \& Bylund, C. L. (eds.) Family communication about genetics: Theory and practice. Oxford, Oxford University Press.

Glaser, B. and Strauss, A., 1967. The discovery ofgrounded theory. London: Weidenfeld and Nicholson.

Green, J. Richards, M. Murton, F. Statham, H. \& Hallowell, N. (1997). Family communication and genetic counselling: The case of hereditary breast and ovarian cancer. Journal of Genetic Counselling. 6, 45-60.

Greene, M., O'Brien, D., Ward, D., Quigley, D., Kelly, F., Carter, G., Durkan, A. \& Farrell, E. (2010) CRY-Cardiac Risk in the Young.

[Online]Available:http://www.cry.ie/index.php?option=com content\&view=article\&id=1\&ltemi $\underline{d=8}[$ Accessed 8th of April 2012].

Hamilton, R. J., Bowers, B. J. \& Williams, J. K. (2005). Disclosing genetic test results to family members. Journal of Nursing Scholarship. 37, 18-24. 
Keehan, K. F., Simdson, S. A., Wilson, B. J., Van Teijlingen, E. R., Mckee, L., Haites, N. \& Matthews, E. (2005). 'It's their blood not mine': Who's responsible for (not) telling relatives about genetic risk? Health Risk \& Society. 7, 209-226.

Kenen, R., Ardern-Jones, A. \& Eeles, R. (2004). We are talking, but are they listening? Communication patterns in families with a history of breast/ovarian cancer (HBOC). PsychoOncology. 13, 335-345.

Koehly, L. M., Peterson, S. K., Watts, B. G., Kempf, K. K. G., Vernon, S. W. \& Gritz, E. R. (2003). A social network analysis of communication about hereditary nonpolyposis colorectal cancer genetic testing and family functioning. Cancer Epidemiology Biomarkers \& Prevention. 12, 304-313.

Koerner, A.F., Leroy, B., \& Veach, P.M. (2010). Family communication patterns. In C.L. Gaff, \& C.L. Bylund (Eds.), Family communication about genetics: Theory and practice (pp. 184198). New York, NY: Oxford University Press.

Lerman, C., Hughes, C., Croyle, R. T., Main, D., Durham, C., Sndyer, C., Bonney, A., et al (2000). Prophylactic surgery decisions and surveillance practices one year following BRCA1/2 testing. Preventive Medicine. 31, 75-80.

Liede, A. Metcalfe, K. Hanna, D. Hoodfar, E. Snyder, C. Durham, C. Lynch, H. T. \& Narod, S. A. (2000). Evaluation of the needs of male carriers of mutations in BRCA1 or BRCA2 who have undergone genetic counselling. American Journal of Human Genetics. 67 (6), 1494-1504.

Mauthner, N. S., \& Doucet, A. (2003). Reflexive accounts and accounts of reflexivity in qualitative data analysis. Sociology. 37(3), 413-431. 
Mcallister M, Evans DGR, Ormiston W, Daly P. (1998). Men in breast cancer families: A preliminary qualitative study of awareness and experience. Journal of Medical Genetics. 35, 739-744.

Mccann, S. Maculey, D. Barnett, Y. Bunting, B. Bradley, A. Jeffers, L. \& Morrison, P. J. (2009). Family communication, genetic testing and colonoscopy screening in hereditary nonpolyposis colon cancer: a qualitative study. Psycho-Oncology. 18 (11), 1208-1215.

Metcalfe, A., Coad, J., Plumridge, G. M., Gill, P. \& Farndon, P. (2008). Family communication between children and their parents about inherited genetic conditions: a meta-synthesis of the research. European Journal of Human Genetics. 16, 1193-1200.

Michie, S., Smith, J. A., Senior, V. \& Marteau, T. M. (2003). Understanding why negative genetic test results sometimes fail to reassure. American Journal of Medical Genetics, Part A. 119A, 340-347.

Ormondroyd, E., Oates, S., Parker, M., Blair, E., \& Watkins, H. (2014). Pre-symptomatic genetic testing for inherited cardiac conditions: a qualitative exploration of psychosocial andethical implications. European Journal of Human Genetics, 22(1), 88-93.

Parrott, R., Miller-Day, M., Peters, K., \& Dillard, J. (2010). Societal, expert, and lay influences. In C.L. Gaff, \& C.L. Bylund (Eds.), Family communication about genetics: Theory and practice (pp. 34-67). New York, NY: Oxford University Press.

Patenaude, A. F., Dorval, M., Digianni, L. S., Schneider, K. A., Chittenden, A. \& Garber, J. E. (2006). Sharing $B R C A 1 / 2$ test results with first-degree relatives: Factors predicting who women tell. Journal of Clinical Oncology. 24, 700-706.

Peterson, S. K. Watts, B. G. Koehly, L. M. Vernon, S. W. Baile, W. F. Kohlmann, W. K. \& Gritz, E. R. (2003). How Families Communicate About HNPCC Genetic Testing: Findings From a Qualitative Study. American Journal of Medical Genetics, Part C. 119C, 78-86. 
Pope, C. \& Mays, N. (1995). Reaching the parts other methods cannot reach - an introduction to qualitative methods in health and health-services research. British Medical Journal. 311, 42-45.

Ritchie, J., Lewis, J., \& Elam, G. (2003). Designing and selecting samples. Qualitative research practice: A guide for social science students and researchers. 77-108.

Rolland, J. S. (2006). Genetics, family systems, and multicultural influences. Families, Systems, \& Health. 24, 425-441.

Smart, A. (2010). Impediments to DNA Testing and Cascade Screening for Hypertrophic Cardiomyopathy and Long QT syndrome: A Qualitative Study of Patient Experiences. Journal of Genetic Counseling. 19, 630-639.

Schaffer, R. Kuczynski, K. \& Skinner, D. (2008). Producing genetic knowledge and citizenship through the Internet: mothers, pediatric genetics, and cybermedicine. Sociology of Health \& IIIness. 30 (1), 145-159.

Shaw, C. Abrams, K. \& Marteau, T. M. (1999). Psychological impact of predicting individuals' risks of illness: a systematic review. Social Science \& Medicine. 49(12), 1571-1598.

Sobel, S. K. \& Cowan, D. B. (2000). Impact of genetic testing for Huntington disease on the family system. American Journal of Medical Genetics. 90, 49-59.

Sobel, S. \& Cowan, C. B. (2003). Ambiguous loss and disenfranchised grief: The impact of DNA predictive testing on the family as a system. Family Process. 42, 47-57.

Smets, E. M. A., Stam, M. M. H., Meulenkamp, T. M., Van Langen, I. M., Wilde, A. A. M., Wiegman, A., De Wert, G. M. \& Tibben, A. (2008). Health-dated quality of life of children with a positive carrier status for inherited cardiovascular diseases. American Journal of Medical Genetics, Part A. 146A, 700-707. 
Strauss, A. \& Corbin, J. (1990). Basics of qualitative research. London. Sage.

Ulph, F., Leong, J., Glazebrook, C. \& Townsend, E. (2010). A qualitative study exploring genetic counsellors' experiences of counselling children. European Journal of Human Genetics. 18, 1090-1094.

Van Den Nieuwenhoff, H. W. P. Gielen, C. \& De Vries, N. K. (2007). Family communication regarding inherited high cholesterol: Why and how do patients disclose genetic risk? Social Science \& Medicine. 65 (5), 1025-1037.

Van Oostrom, I., Meijers-Heijboer, H., Duivenvoorden, H. J., Brocker-Vriends, A. H. J. T., Van Asperen, C. J., Sijmons, R. H., Seynaeve, C., et al (2007a). A prospective study of the impact of genetic susceptibility testing for BRCA1/2 or HNPCC on family relationships. Psycho-Oncology. 16, 320-328.

Van Oostrom, I., Meijers-Heijboer, H., Duivenvoorden, H. J., Brocker-Vriends, A. H. J. T., Van Asperen, C. J., Sijmons, R. H., Seynaeve, C., et al (2007b). Family system characteristics and psychological adjustment to cancer susceptibility genetic testing: A prospective study. Clinical Genetics. 71, 35-42.

Wagner Costalas, J., Itzen, M., Malick, J., Babb, J. S., Bove, B., Godwin, A. K. \& Daly, M. B. (2003). Communication of $B R C A 1$ and $B R C A 2$ results to at-risk relatives: a cancer risk assessment program's experience. American journal of medical genetics, Part $C$, Seminars in medical genetics. 119C, 11-8.

Weiner, J.L., Silk, K.J., \& Parrott, R.L. (2005). Family communication about genetic health: A research note. The Journal of Family Communication. 5, 313-324.

White, L. \& Riedmann, A. (1992). Ties among adult siblings. Social Forces. 71 (1), 85-102. 
Wilson, B.J., Forrest, K., Van Teijlingen, E.R., Mckee, L., Haites, N., Matthews, E., \&

Simpson, S.A. (2004). Family communication about genetic risk: The little that is known.

Community Genetics. 7, 15-24.

\section{Conflict of Interest}

Sinead Whyte declares that she has no conflict of interest.

Hannah Shipman declares that she has no conflict of interest.

Dr Marion McAllister declares that she has no conflict of interest.

Professor Andrew Green declares that he has no conflict of interest. 